\title{
Comparison of the effects of inhaled ipratropium bromide and salbutamol on the bronchoconstrictor response to hypocapnic hyperventilation in normal subjects
}

\author{
J P JAMISON, P J GLOVER, W F M WALLACE \\ From the Department of Physiology, Queen's University, Belfast
}

\begin{abstract}
A double blind, placebo controlled comparison was made of the effects of nebulised ipratropium bromide (0.05 and $0.5 \mathrm{mg})$ and salbutamol $(0.25$ and $2.5 \mathrm{mg})$ on lung function and the airway response to hyperventilation in eight normal subjects. Both agents at both doses caused similar baseline bronchodilatation, confirming the presence of resting bronchomotor tone. The overall mean increases as percentages of control were $33 \%$ in specific airway conductance (sGaw), $10 \%$ in maximal flow after expiration of $50 \%$ of vital capacity, and $3.7 \%$ in FEV . Hypocapnia (mean end tidal carbon dioxide tension $2 \cdot 2 \mathrm{kPa}$ ) was produced by three minutes of voluntary hyperventilation and resulted in a mean fall in sGaw of $0.49 \mathrm{~s}^{-1} \mathrm{kPa}^{-1}(20 \%)$. After inhalation of $0.25 \mathrm{mg}$ salbutamol hypocapnic hyperventilation still produced a mean fall in sGaw of $0.55 \mathrm{~s}^{-1}$ $\mathrm{kPa}^{-1}$, whereas salbutamol $2.5 \mathrm{mg}$ reduced this response to $0 \cdot 15 \mathrm{~s}^{-1} \mathrm{kPa}^{-1}(6 \%)$. After both doses of ipratropium the decrease in sGaw caused by hyperventilation was similar to the control. This suggests that bronchoconstriction in response to hypocapnic hyperventilation in normal subjects is not mediated via a cholinergic reflex.
\end{abstract}

Hypocapnic hyperventilation in normal subjects has been shown to cause bronchoconstriction, ${ }^{1-3}$ unlike isocapnic hyperventilation. ${ }^{3}$ The constrictor response to hypocapnia may be due to a reflex action or to a direct action on airway smooth muscle. It has been reported that pretreatment with a $\beta$ agonist blocked the response whereas atropine pretreatment did not, ${ }^{4}$ suggesting a non-cholinergic mechanism for this effect of hypocapnia. Consistent with this hypothesis, more severe hypocapnia produced by unilateral pulmonary artery occlusion ${ }^{5}$ caused a shift of ventilation towards the normally perfused lung; this effect could be inhibited by a $\beta$ agonist or by $6 \%$ carbon dioxide but vagotomy had no effect. In contrast, Newhouse et $a l^{1}$ and Sterling ${ }^{2}$ found that atropine pretreatment did reduce hypocapnia induced bronchoconstriction,

Address for reprint requests: Dr J P Jamison, Department of Physiology, Medical Biology Centre, 97 Lisburn Road, Belfast, BT9 7BL.

Accepted 23 March 1987 indicating that cholinergic mechanisms might have a role in the response.

This study is a further investigation into the mechanism of the bronchoconstrictor response to hypocapnia in normal subjects with the use of the cholinergic antagonist $N$-isopropyl atropine (the quaternary derivative of atropine)- that is, ipratropium bromide. ${ }^{6}$ Voluntary hyperventilation was carried out in a manner shown previously in this laboratory to cause bronchoconstriction that is entirely dependent on hypocapnia. ${ }^{3}$ Since one explanation for the blockade of the airway response to hyperventilation by atropine in previous studies may have been airway dilatation after drug administration, a control for this was provided by giving salbutamol in a dose that caused a degree of bronchodilatation similar to that of ipratropium.

Since hypocapnia may occur in severe asthma, ${ }^{7}$ the findings of this study may be relevant to the treatment of severe asthma or asthmatic attacks triggered by hypocapnic hyperventilation. 
Methods

SUBJECTS

Eight normal men aged 18-49 years participated. The experiments had the approval of the research ethical committee and all subjects gave fully informed consent. A clinical history was taken to exclude disease, especially respiratory disease, heart disease, epilepsy, and allergy to atropine. All subjects refrained from tea, coffee, and cigarette smoke for at least an hour before the experiments. All had previously been trained in carrying out the manoeuvres necessary for the lung function tests.

\section{MEASUREMENTS}

Specific airway conductance (sGaw) and thoracic gas volume (TGV) were measured with a computerised, constant volume, whole body plethysmograph (PK Morgan). The subject panted at a frequency of $2 \mathbf{H z}$ at a flow rate of $0.5-1.01 \mathrm{~s}^{-1}$, and the resulting signals were recorded on photographic paper with a fibreoptic facility. The data were digitised and sGaw and TGV were calculated by computer, by fitting slopes by linear regression to whole loop single breaths. Five measurements were made at 15 second intervals, followed by four at 30 second intervalsnine measurements in a three minute period. The response to hyperventilation was assessed by comparing the mean of nine such measurements immediately before hyperventilation with corresponding measurements immediately after hyperventilation.

Forced expiratory measurements were made with a computerised bellows spirometer (McDermott). Flow-volume curves were plotted and forced expiratory volumes in one second $\left(\mathrm{FEV}_{1}\right)$, forced vital capacity (FVC), and maximal flow rates at $50 \%$ of FVC $\left(\dot{V}^{2} a_{50}\right)$ were calculated by online computer.

\section{HY PER VENTILATION}

The subject was asked to breathe room air in time with a metronome at a frequency of $1 \mathrm{~Hz}$ for three minutes. Feedback display of the pneumotachograph flow rate signal on an oscilloscope screen was used to help the subjects control their depth of breathing. Tidal volume was recorded continuously on a chart recorder by integrating the pneumotachograph flow signal. Effective minute ventilation was calculated from tidal volume corrected for apparatus deadspace and any integrator drift. The accuracy of this method of measuring ventilation was confirmed in pilot experiments by collecting timed expirate in a water filled spirometer.

End tidal $\mathrm{PCO}_{2}$ was determined from gas sampled from the mouthpiece as a continuous recording of percentage carbon dioxide $\left(\% \mathrm{CO}_{2}\right)$ by the use of a mass spectrometer (Centronics MGA 200).
PROTOCOL

Each experiment consisted of prehyperventilatio control measurements of sGaw and TGV over threes minutes followed by repeat measurements immedic ately after three minutes' hyperventilation. Fiv $\widehat{\oplus}$ forced expirations were then made to obtain mean values of $F E V_{1}, F V C$, and $\dot{V} \max _{50}$. The subject theff inhaled, in a double blind manner, one of the follow ing five preparations at random: (1) $2.0 \mathrm{ml}$ isotonic. saline; (2) $0.25 \mathrm{mg}$ salbutamol in $2 \mathrm{ml}$ saline; (3) $2.5 \mathrm{~m}$ salbutamol in $2 \mathrm{ml}$ saline; (4) $0.05 \mathrm{mg}$ ipratropiur bromide in $2 \mathrm{ml}$ saline; (5) $0.5 \mathrm{mg}$ ipratropium bro mide in $2 \mathrm{ml}$ saline.

The subject inhaled, using normal tidal breathing, from a Wright's nebuliser driven by $100 \%$ oxygen as a flow rate of $71 \mathrm{~min}^{-1}$. The lung function tests an $\$$ hyperventilation were repeated 45 minutes after the start of inhalation. The experiment was repeated with each of the five agents on every subject, with an inter val of at least 24 hours between experiments. Hear rate was measured from the radial pulse at the end of each set of lung function measurements before and after inhalation of the drug.

STATISTICAL ANALYSIS

Logarithmic transformation, $\log _{e}(1+s G a w)$, was carried out to normalise sGaw before statistic analysis was performed. ${ }^{89}$ Paired $t$ tests were used to analyse the changes in $\mathrm{PCO}_{2}$ and $\mathrm{sGaw}$ with hypep ventilation and the effect of drugs on baseline lun $\vec{g}$ function measurements and heart rate. Analysis of variance was used to investigate the effect of placeb and drugs on the change in sGaw with hyperventilation. Paired $t$ tests were carried out at corres ponding time points before and after hyperventilatio o to determine the times at which the differences in response to hyperventilation were significant. The results are given as means with standard errors in parentheses.

\section{Results}

HY PER VEN TILATION

The required rate and depth of breathing, observed bs oscilloscope during hyperventilation, was maintained by all subjects on every occasion. Because of technica思 failures permanent recordings of minute volume an $\AA^{\circ}$ $\mathrm{PCO}_{2}$ were not complete. The means of those obtainee are shown in table 1 . The mean minute ventilation during hyperventilation was 55.9 (SEM 1.0)1 $\mathrm{min}^{-}{ }_{\mathrm{O}}$ (range 39.4-73.8 $1 \mathrm{~min}^{-1}$ ). Ventilation did not differ significantly between study days either before or aftes drug inhalation.

End tidal $\mathrm{PCO}_{2}$ was measured in 32 experiment before drug inhalation and in 31 experiments after ip The $\mathrm{PCO}_{2}$ fell quickly initially but more slowly 
Table 1 Minute ventilation and corresponding end tidal carbon dioxide tension $\left(\mathrm{Pco}_{2}\right)$ before (control) and after hyperventilation, before and after drug inhalation (means with standard errors in parentheses)*

\begin{tabular}{|c|c|c|c|c|c|c|c|c|c|c|c|}
\hline & & \multirow{2}{*}{\multicolumn{2}{|c|}{ Placebo }} & \multicolumn{4}{|c|}{ Ipratropium (mg) } & \multicolumn{4}{|c|}{ Salbutamol (mg) } \\
\hline & & & & \multicolumn{2}{|l|}{0.05} & \multicolumn{2}{|l|}{0.5} & \multicolumn{2}{|l|}{$0 \cdot 25$} & \multicolumn{2}{|l|}{$2 \cdot 5$} \\
\hline & & Before & After & Before & After & Before & After & Before & After & Before & After \\
\hline \multicolumn{2}{|c|}{ Minute ventilation $\left(1 \min ^{-1}\right)$} & $\begin{array}{l}54 \cdot 3 \\
(3 \cdot 9)\end{array}$ & $\begin{array}{l}54 \cdot 8 \\
(2 \cdot 9)\end{array}$ & $\begin{array}{l}55 \cdot 4 \\
(3 \cdot 3)\end{array}$ & $\begin{array}{l}53 \cdot 3 \\
(3 \cdot 4)\end{array}$ & $\begin{array}{l}53 \cdot 4 \\
(3.0)\end{array}$ & $\begin{array}{l}58.6 \\
(3.2)\end{array}$ & $\begin{array}{c}58 \cdot 2 \\
(2 \cdot 7)\end{array}$ & $\begin{array}{l}56.7 \\
(2.2)\end{array}$ & $\begin{array}{l}56 \cdot 8 \\
(3 \cdot 1)\end{array}$ & $\begin{array}{l}59.9 \\
(3.8)\end{array}$ \\
\hline $\begin{array}{l}\mathrm{Pco}_{2} \\
(\mathrm{kPa})\end{array}$ & $\begin{array}{l}\text { Control } \\
\text { Hyperventilation }\end{array}$ & $\begin{array}{c}\mathrm{n} \\
5.26 \\
(0 \cdot 11) \\
2.24 \\
(0.05) \\
n=7\end{array}$ & $\begin{array}{c}8.42 \\
(0.16) \\
2.19 \\
(0.05) \\
n=7\end{array}$ & $\begin{array}{c}\mathrm{n}= \\
5 \cdot 28 \\
(0 \cdot 11) \\
2 \cdot 20 \\
(0 \cdot 11) \\
\mathrm{n}=7\end{array}$ & $\begin{array}{c}7.31 \\
(0.07) \\
2.17 \\
(0.09) \\
\mathrm{n}=7\end{array}$ & $\begin{array}{c}\mathrm{n}= \\
5 \cdot 14 \\
(0 \cdot 16) \\
2 \cdot 20 \\
(0 \cdot 12) \\
\mathrm{n}=7\end{array}$ & $\begin{array}{c}5.12 \\
(0.09) \\
2.07 \\
(0.09) \\
n=7\end{array}$ & $\begin{array}{c}\mathrm{n}= \\
5 \cdot 16 \\
(0 \cdot 19) \\
2 \cdot 21 \\
(0 \cdot 13) \\
\mathrm{n}=6\end{array}$ & $\begin{array}{c}8.28 \\
(0.31) \\
2 \cdot 12 \\
(0 \cdot 12) \\
n=5\end{array}$ & $\begin{array}{c}\mathrm{n}= \\
5.40 \\
(0.08) \\
2 \cdot 39 \\
(0 \cdot 17) \\
\mathrm{n}=5\end{array}$ & $\begin{array}{c}5.48 \\
(0.04) \\
2.09 \\
(0.07) \\
n=5\end{array}$ \\
\hline
\end{tabular}

*None of the mean values before and after placebo or drug on any study day differed significantly ( $\mathrm{p}>0.5$ ); in all cases Pco ${ }_{2}$ fell during hyperventilation $(p<0.001)$.

$\mathrm{n}$-number of observations.

hyperventilation progressed. Before drug inhalation the mean end tidal $\mathrm{PCO}_{2}$ while subjects were breathing at rest was $5.26(0.05) \mathrm{kPa}$, falling to $2.24(0.05) \mathrm{kPa}$ at the end of hyperventilation $(\mathrm{p}<0.001)$. After drug inhalation the values averaged $5.32(0.07) \mathrm{kPa}$ and $2 \cdot 14(0.04) \mathrm{kPa}$ respectively. There was no significant difference between mean values for the five study days either before or after placebo and drugs (table 1).

EFFECT OF HYPER VENTILATION ON SGAW Hyperventilation led to a fall in sGaw in all subjects $(p<0.001)$, and this was greatest in the first 30 seconds (fig 1). sGaw then gradually increased, and was not significantly different from the control value at two minutes.

Before drug inhalation mean sGaw over the three minute recording periods fell from $2.42(0 \cdot 1) \mathrm{s}^{-1}$ $\mathrm{kPa}^{-1}$ before hyperventilation to $1.93(0.12) \mathrm{s}^{-1}$ $\mathrm{kPa}^{-1}$ after hyperventilation $(\mathrm{p}<0.0005)$, a fall of $20 \%$. Mean TGV was 3.881 before and 3.941 after hyperventilation $(p>0 \cdot 24)$.

\section{EFFECT OF DRUGS ON BASELINE LUNG FUNCTION AND RESPONSE TO HYPER VENTILATION}

All inhalations apart from that of isotonic saline pro-

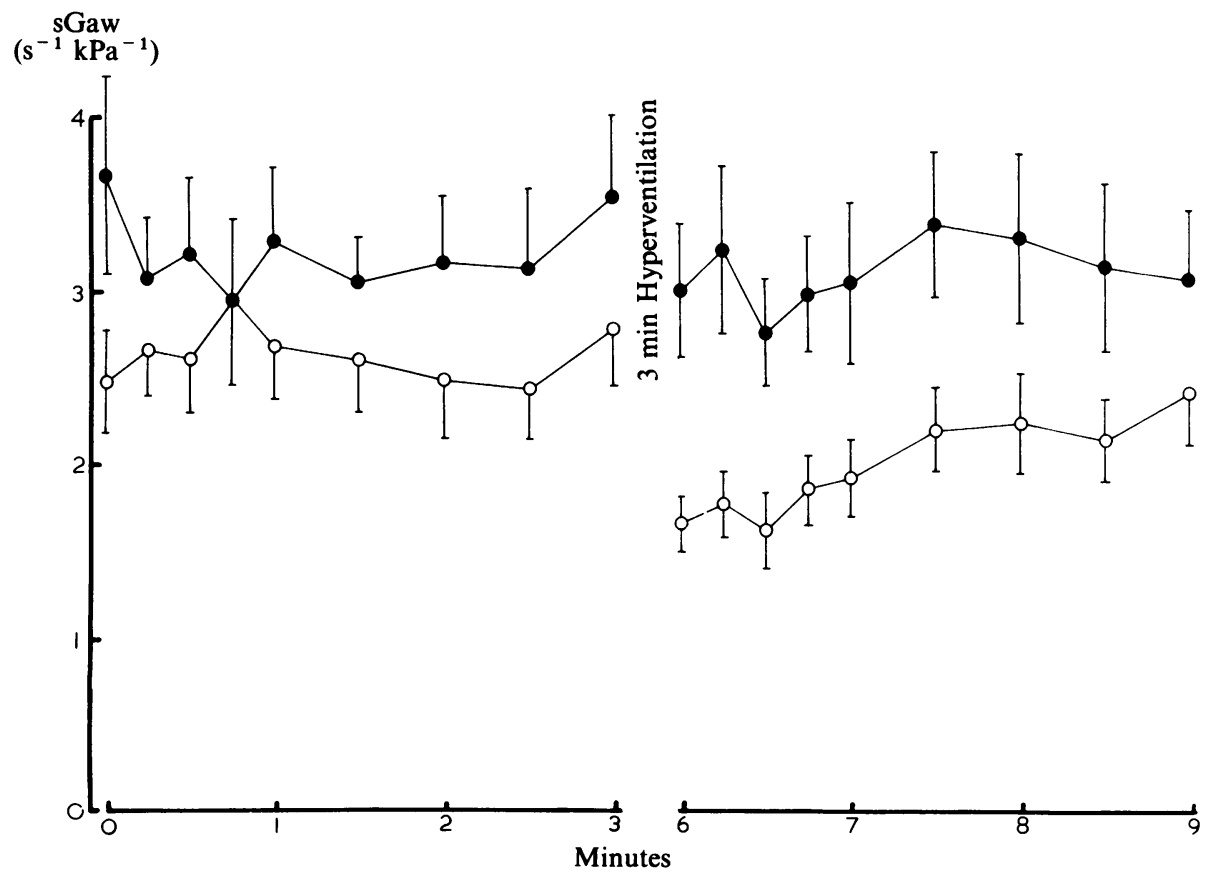

Fig 1 Mean specific airway conductance (sGaw) (with standard errors) for all eight subjects before (○) and after (O) inhalation of $2.5 \mathrm{mg}$ salbutamol. 
Table 2 Effect of inhalations on baseline specific airway conductance (sGaw, $s^{-1} \mathrm{kPa}^{-1}$ ) in eight subjects (means with standard errors in parentheses)

\begin{tabular}{|c|c|c|c|c|c|}
\hline & \multirow[t]{2}{*}{ Placebo } & \multicolumn{2}{|c|}{ Ipratropium (mg) } & \multicolumn{2}{|c|}{ Salbutamol (mg) } \\
\hline & & 0.05 & $0 \cdot 5$ & $0 \cdot 25$ & $2 \cdot 5$ \\
\hline $\begin{array}{l}\text { Baseline sGaw } \\
\text { Change in sGaw after inhalation } \\
\mathrm{p}\end{array}$ & $\begin{array}{c}2.41(0.09) \\
0.08 \\
>0.7\end{array}$ & $\begin{array}{c}2.46(0 \cdot 10) \\
0.80 \\
<0.001\end{array}$ & $\begin{array}{c}2 \cdot 35(0 \cdot 10) \\
1.06 \\
<0.01\end{array}$ & $\begin{array}{c}2 \cdot 28(0 \cdot 10) \\
0.73 \\
<0.01\end{array}$ & $\begin{array}{c}2.63(0 \cdot 10) \\
0.60 \\
<0.05\end{array}$ \\
\hline
\end{tabular}

duced a significant increase in sGaw over the preinhalation values (table 2 , fig 2 ) and over the isotonic saline value $(\mathrm{p}<0.05)$ in each case). Ipratropium produced a slightly greater increase in sGaw than salbutamol but this was not significant for either dose. Mean TGV was 3.91 1 before inhalation and 3.91 1 after inhalation. There was an increase in both $\mathrm{FEV}_{1}$ and $\dot{V} \max _{50}$ after low and high doses of both active drugs (fig 2) and no change in these measurements after isotonic saline. There was no significant change in FVC.

The effects of the two drugs on the response to hyperventilation are shown in figure 3 and table 3 . Isotonic saline, both doses of ipratropium, and the lower dose of salbutamol failed to alter the fall in sGaw produced by hyperventilation significantly. In contrast, the higher dose of salbutamol prevented the change after hyperventilation. After $2.5 \mathrm{mg}$ salbutamol the fall in sGaw with hyperventilation of $0 \cdot 15$ $\mathrm{s}^{-1} \mathrm{kPa}^{-1}$ was significantly less $(\mathrm{p}<0.04)$ than the fall after isotonic saline (see fig 1).
Inhalation of $2.5 \mathrm{mg}$ salbutamol increased the hear $\vec{\xi}$ rate from 71 to 82 beats/min $(p<0.05)$ and severa subjects reported slight tremor. None of the other inhalations produced tremor or a significant change iñ heart rate.

\section{Discussion}

The present results agree with those of other workers, ${ }^{1-410}$ in showing that hypocapnic hypero ventilation in normal subjects causes an increase iro resistance to flow. We have reported in a previous study $^{3}$ using identical techniques that the effective. stimulus for bronchoconstriction is the fall in Pco since isocapnic hyperventilation did not change air way resistance. Sterling ${ }^{2}$ reported an end tidal $\mathrm{PCO}_{2}$ of $27.5 \mathrm{mmHg}(3.66 \mathrm{kPa})$ with hyperventilation and $37 \%$ decrease in airway conductance. In the present study end tidal $\mathrm{PCO}_{2}$ fell to a lower level, $16.5 \mathrm{~mm} \mathrm{H}$ $(2 \cdot 2 \mathrm{kPa})$. Although the mean fall in sGaw of $20 \%$ over the three minutes of the recording was less that $\overrightarrow{5}$

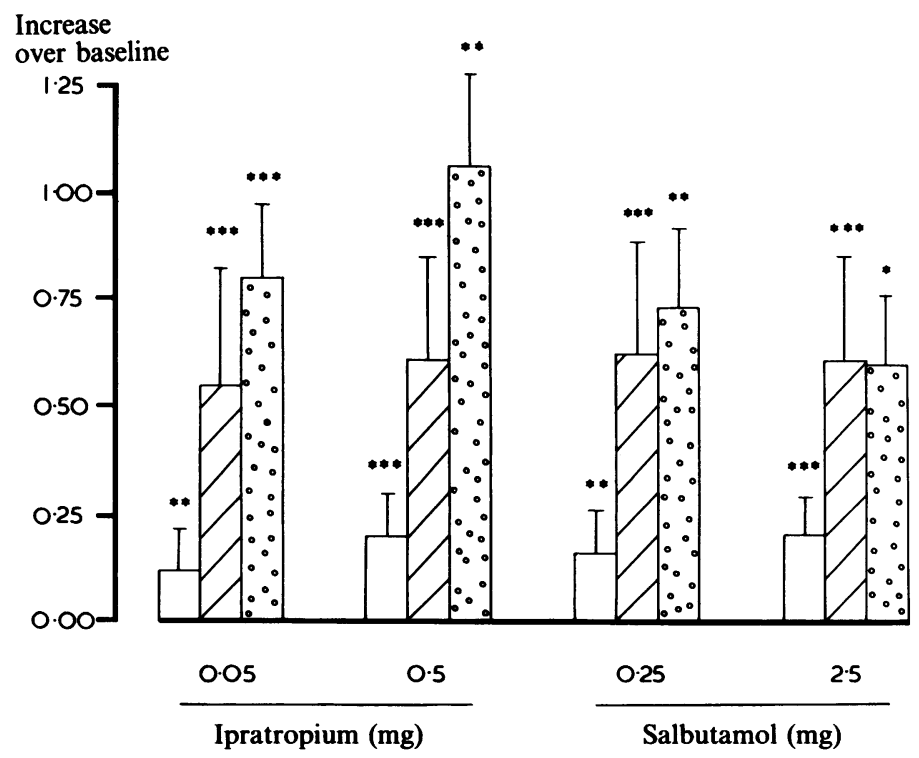

Fig 2 Mean increases in FEV (1: $\square)$, maximal flow at $50 \%$ of vital capacity ( $\max _{\mathrm{so}}, l \mathrm{~s}^{-1}$ : and specific airway conductance (sGaw, $\mathrm{s}^{-1} \mathrm{kPa}^{-1}:[9$ ) after inhalation of ipratropium and salbutamol in the doses shown. ${ }^{*} \mathrm{p}<0.05 ;{ }^{* *} \mathrm{p}<0.01$; $* * * \mathrm{p}<0.001$. 


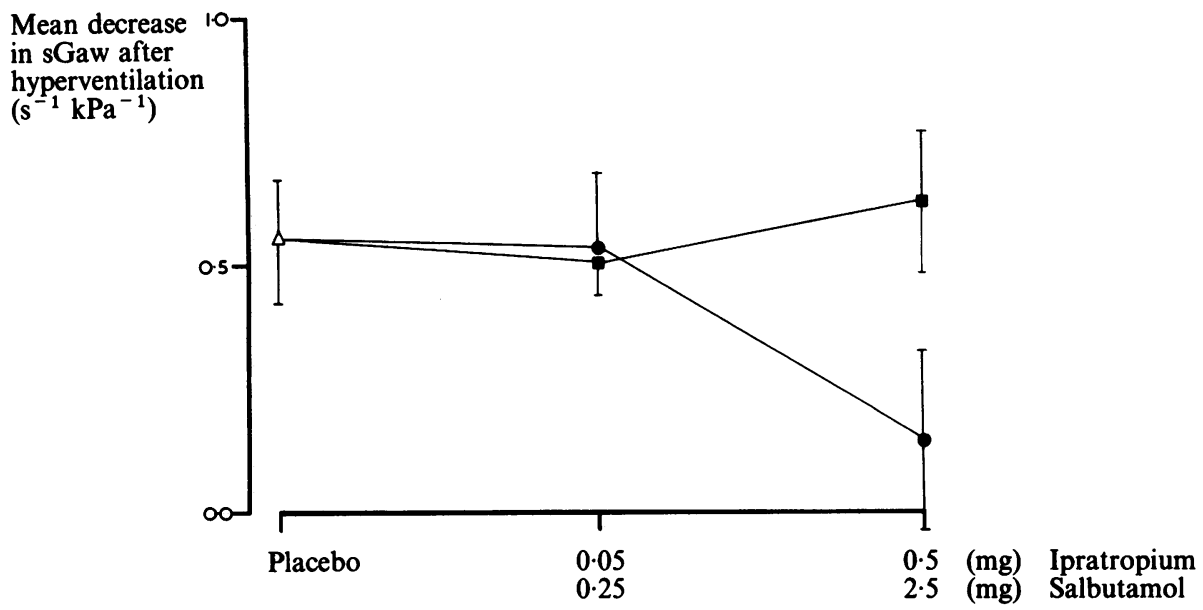

Fig 3 Mean decreases (with standard errors) in specific airway conductance (sGaw) for all eight subjects with hyperventilation after inhalation of ipratropium ( $\square$ ), salbutamol (O), and placebo $(\triangle)$.

that seen by Sterling, the fall in the first minute was of similar magnitude (fig 1). Because of different techniques and time courses of recording our results cannot be compared strictly with those from other studies, but they are of the same order. ${ }^{2310}$

The doses of each drug used lie within the normal therapeutic range, the low doses being equivalent to that delivered by 2-3 aerosol inhaler puffs and the high doses similar to those given by nebuliser to patients with severe asthma and chronic bronchitis. Measurements were made 45 minutes after inhalation, when the drug effect should be maximal. ${ }^{11-13}$ The results confirmed that in normal subjects there is resting bronchomotor tone that can be released by either cholinergic blockade or $\beta$ adrenoceptor stimulation. ${ }^{213-16}$ Maximal dilatation occurred with the low dose of each drug and there was no significant difference between drugs. The response was not dose dependent, suggesting maximal effective blockade by the cholinergic antagonist and maximal effective response to the $\beta_{2}$ stimulant.
The size of the airways affected by anticholinergic and $\beta$ agonist drugs is controversial. It has been reported that anticholinergic drugs predominantly dilate larger, central airways while $\beta$ agonists predominantly dilate smaller, peripheral airways, ${ }^{141517}$ a conclusion not confirmed by MacNee et al. ${ }^{13}$ In the present results the trend was for cholinergic blockade to have a greater effect on conductance (large airways ${ }^{18}$ ), while the drugs had similar effects on $\dot{V}_{\max }{ }_{50}$ (more peripheral airways ${ }^{19}$ ). The differences between the drugs were not, however, significant, and differentiation of the preferential sites of action of drugs by comparison of drug effects on conductance and flow rates is not very reliable. ${ }^{20}$ It is not possible from the present experiments to determine whether differences between the two drugs could be due to a difference in the site of action.

The results indicate that the bronchoconstrictor response to hypocapnic hyperventilation is not dependent on baseline bronchomotor tone since the constriction response to hyperventilation after the

Table 3 Postinhalation specific airway conductance (sGaw, $s^{-1} \mathrm{kPa}^{-1}$ ) before and after hyperventilation in eight subjects (means with standard errors in parentheses)

\begin{tabular}{|c|c|c|c|c|c|c|c|c|c|c|}
\hline & \multirow{2}{*}{\multicolumn{2}{|c|}{$\begin{array}{l}\text { Isotonic } \\
\text { saline }\end{array}$}} & \multicolumn{4}{|c|}{ Ipratropium (mg) } & \multicolumn{4}{|c|}{ Salbutamol (mg) } \\
\hline & & & \multicolumn{2}{|l|}{0.05} & \multicolumn{2}{|l|}{0.5} & \multicolumn{2}{|l|}{$0 \cdot 25$} & \multicolumn{2}{|l|}{$2 \cdot 5$} \\
\hline & Before & After & Before & After & Before & After & Before & After & Before & After \\
\hline sGaw & $\begin{array}{c}2.49 \\
(0 \cdot 10)\end{array}$ & $\begin{array}{c}1.83 \\
(0.07)\end{array}$ & $\begin{array}{c}3 \cdot 26 \\
(0 \cdot 14)\end{array}$ & $\begin{array}{c}2.76 \\
(0.13)\end{array}$ & $\begin{array}{c}3.41 \\
(0.18)\end{array}$ & $\begin{array}{c}2.78 \\
(0.12)\end{array}$ & $\begin{array}{c}3.01 \\
(0.16)\end{array}$ & $\begin{array}{c}2.46 \\
(0 \cdot 13)\end{array}$ & $\begin{array}{c}3.23 \\
(0.13)\end{array}$ & $\begin{array}{c}3.08 \\
(0.13)\end{array}$ \\
\hline $\begin{array}{l}\Delta \text { sGaw } \\
\text { p }\end{array}$ & \multicolumn{2}{|c|}{$\begin{array}{c}0.66 \\
(0.12) \\
<0.001\end{array}$} & \multicolumn{2}{|c|}{$\begin{array}{c}0.50 \\
(0.19) \\
<0.001\end{array}$} & \multicolumn{2}{|c|}{$\begin{array}{c}0.63 \\
(0.22) \\
<0.05\end{array}$} & \multicolumn{2}{|c|}{$\begin{array}{c}0.55 \\
(0.21) \\
<0.001\end{array}$} & \multicolumn{2}{|c|}{$\begin{array}{c}0.15 \\
(0.18) \\
>0.3\end{array}$} \\
\hline
\end{tabular}


two doses of ipratropium and the low dose of salbutamol was similar to that seen after isotonic saline, despite the substantial bronchodilatation.

Previous studies investigating the role of cholinergic mechanisms in the production of hypocapnic airway constriction have produced conflicting results. Sterling $^{2}$ found evidence for such a mechanism in man. Before intravenous atropine hypocapnic hyperventilation reduced airway conductance by $37 \%$, whereas after atropine the reduction was only $7 \%$. In contrast, O'Cain et al, ${ }^{4}$ measuring partial expiratory flow-volume curves, found that the bronchoconstrictor response to hypocapnic hyperventilation was reduced by a $\beta$ sympathomimetic agent but not by inhaled atropine. Severinghaus $e t a l^{5}$ were unable to block the response in the dog either by vagotomy or by intramuscular or intravenous atropine.

In the present study high doses of inhaled ipratropium did not impair the bronchoconstrictor response to hyperventilation. Inhalation is an effective route for bronchodilator treatment. In asthmatic patients terbutaline inhalation was found to be as effective as intravenous infusion, and no difference between measures of large and small airway responses was detectable. ${ }^{21}$ Airways inaccessible to inhaled ipratropium are unlikely to take part in the conductance response to hypocapnia. The high dose of ipratropium was 10 times the low dose, which itself was sufficient to achieve maximal blockade of resting bronchomotor tone. It is difficult to envisage how any vagal cholinergic reflex would not be affected by this high dose of an anticholinergic agent that is more potent than atropine, ${ }^{6}$ especially as the response could be blocked by inhalation of the $\beta_{2}$ stimulant salbutamol.

These results are thus consistent with most previous studies in rejecting the role of cholinergic receptors in the bronchoconstrictor response to hypocapnia. Possible alternative mechanisms would be a direct effect of carbon dioxide or $\mathrm{pH}$ on airway smooth muscle, release of a short acting mediator, or non-cholinergic nerves.

\section{References}

1 Newhouse MT, Becklake MR, Macklem PT, MacGregor M. Effect of alterations in end-tidal $\mathrm{CO}_{2}$ tension on flow resistance. J Appl Physiol 1964;19:745-9.

2 Sterling GM. The mechanism of bronchoconstriction due to hypocapnia in man. Clin Sci 1968;34:277-85.

3 Moohan JM, Bullock CA, Jamison JP, Wallace WFM. The effect of a fall in the level of end-tidal carbon dioxide on specific airways conductance in man. Ir $J$ Med Sci 1985; 154:325.

4 O'Cain CF, Hensley MJ, McFadden ER, Ingram RH. Pattern and mechanism of airway response to hypocapnia in normal subjects. $J$ Appl Physiol
1979;47:8-12.

5 Severinghaus JW, Swenson EW, Finley TN, Lategola $\bar{\partial}$ MT, Williams J. Unilateral hypoventilation produced $\bar{\sigma}$ in dogs by occluding one pulmonary artery. J Appl $\overline{\bar{\omega}}$ Physiol 1961;16:53-60.

6 Engelhardt A. Pharmacology and toxicology of Atrovent. Scand J Respir Dis 1979;103:110-5.

7 Rebuck AS, Read J. Assessment and management of $\vec{\circ}$ severe asthma. Am J Med 1971;51:788-98.

8 Guyatt AR, Alpers JH. Factors affecting airway conduc- $\vec{\omega}$ tance: a study of 752 working men. J Appl Physiol 1968;24:310-6.

9 Viljanen AA, Viljanen BC, Haltunen PK, Kreus KE. Body plethysmographic studies in non-smoking, ? healthy adults. Scand J Clin Lab Invest 1981;4(suppl $\vec{\circ}$ 159):35-50.

10 Twort CHC, Neild JE, Cameron IR. The effect of $\mathscr{Q}$ verapamil and inspired $\mathrm{CO}_{2}$ on the bronchoconstriction provoked by hyperventilation in normal humans. Clin Sci 1985;69:361-364.

11 Pakes GE, Brogden RN, Heel RC, Speight TM, Avery GS. Ipratropium bromide: a review of its pharmacological properties and therapeutic efficacy in asthma and chronic bronchitis. Drugs 1980;20:237-266.

12 Walters EH, Cockroft A, Griffiths T, Rocchiccioli K, Davies BH. Optimal dose of salbutamol respiratory : solution: comparison of three doses with plasma levels. Thorax 1981;36:625-628.

13 MacNee W, Douglas NJ, Sudlow MF. Effects of drug inhalation of $\beta$-sympathomimetic and atropine-like drugs on airway calibre in normal subjects. Clin Sci 요 1982;63:137-143.

14 Detroyer A, Yernault JC, Rodenstein D. Effects of vagal $\overline{\bar{O}}$ blockade on lung mechanics in normal man. $J$ Appl Physiol 1979;46:217-226.

15 Hensley MJ, O'Cain CF, McFadden ER, Ingram RH. Distribution of bronchodilatation in normal subjects: beta agonist versus atropine. $J$ Appl Physiol 으 1978;45:778-782.

16 Holgate ST, Baldwin CJ, Tattersfield AE. $\beta$-adrenergic resistance in normal human airways. Lancet 1977;ii:375-377.

17 Ingram RH, Wellmann JJ, McFadden ER, Mead J. Relative contributions of large and small airways to flow limitation in normal subjects before and after 윽 atropine and isoproterenol. $J$ Clin Invest 1977;59:696-703.

18 Macklem PT, Woolcock JC, Hogg JC, Nadel JA, Wilson NJ. Partitioning of pulmonary resistance in the dog. $J$ S Appl Physiol 1969;26:798-805.

19 Mead J, Turner JN, Macklem PT, Little JB. Significance N of the relationship between lung recoil and maximal $\omega$ expiratory flow. J Appl Physiol 1967;22:95-108.

20 Bottrill I, Hardy C, Sterling GM, Holgate ST. Do measurements of airway calibre, lung volumes and $\mathbb{D}$ compliance differentiate preferential sites of action of bronchoconstrictor agents? [abstract]. Thorax 1985; Ч 40:718

21 Pierce RJ, Payne CR, Williams SJ, Denison D, Clark TJH. Comparison of intravenous and inhaled ter- $\mathbb{D}$ butaline in the treatment of asthma. Chest 1981;79:506-11. 